\title{
Mitochondrial Replacement Therapy: Modifying Genes to Prevent Inherited Mitochondrial Disease
}

\section{Jennifer Kramer}

\section{University of Saskatchewan}

Mitochondrial replacement therapy (MRT) is a novel reproductive technique with the potential to help families have genetically related children born free of devastating mitochondrial DNA (mtDNA) disease that would otherwise be inherited. While the bulk of genetic material lies inside the nuclei of cells, a small amount exists in tiny structures called mitochondria that are only passed to the child from the mother. The genes here do not affect characteristics such as appearance, height, or intelligence. Rather they support the function of mitochondria, to use oxygen to turn the body's food into energy. Cells need energy to survive so without healthy mitochondria a broad spectrum of progressive and debilitating diseases of the brain, muscles, liver, heart, and kidneys can result ${ }^{1}$. A national charity estimates that at least one in 5000 Canadians have some form of mtDNA disease ${ }^{2}$. There is no cure but today there is hope. Exciting evidence from American and British scientists suggests that replacing mitochondrial mutations with healthy genes can prevent the transmission of mtDNA disease ${ }^{3,4}$. After intense debate, the United Kingdom is set to begin clinical trials of MRT later this year ${ }^{5}$. The aims of this article are to present the arguments and implications surrounding this cutting-edge technology.

MRT

MRT is an innovative in-vitro fertilization (IVF) technique where an embryo is created with the nucleus DNA from its parents but the mitochondrial DNA from a donor woman. Proposed methods include repairing the embryo (figure 1) and repairing the egg (figure 2) ) $^{3,4}$. Both result in a permanent change that would be passed on throughout the generations.

\section{Safety, Risk, and Ethical concerns}

Because science has yet to understand how nuclear and mitochondrial genomes interact with one another, the benefits and risks of MRT are unclear. Like all new technologies, these questions cannot be answered until human trials are conducted and several generations are followed. How much evidence is needed before moving forward has been rigorously debated in the UK. The

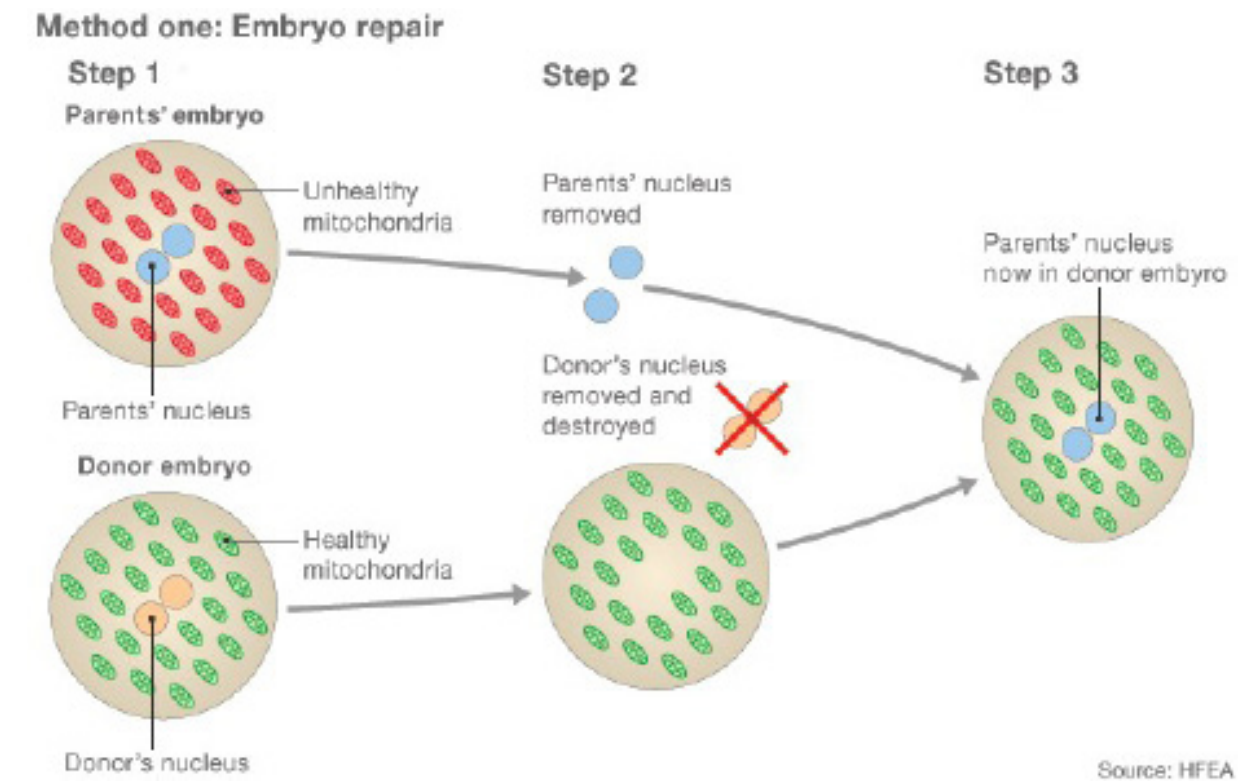

Figure 1. Step 1: Two eggs are fertilised with sperm, creating an embryo from the intended parents and another from the donors. Step 2: The pronuclei, which contain genetic information, are removed from both embryos but only the parents' are kept. Step 3: A healthy embryo is created by adding the parents' pronuclei to the donor embryo, which is finally implanted into the womb $\mathrm{m}^{3}$. 
third scientific review by the Human Fertilisation and Embryology Authority (HFEA) concludes that nothing indicates MRT is unsafe ${ }^{6}$, but the unknown carries a degree of risk. A degree that supporters of MRT argue that, with informed consent, is outweighed by the need for the procedure in preventing cruel and life-shortening inherited diseases.

Mitochondrial replacement therapy raises several ethical questions. Religious opinions vary depending on affiliation, ranging from strong objections on the claim that embryos and adults have equal moral status, to acceptance since the purpose of $M R T$ is to ease human suffering. Fears similar to the IVF debate in the 1970s

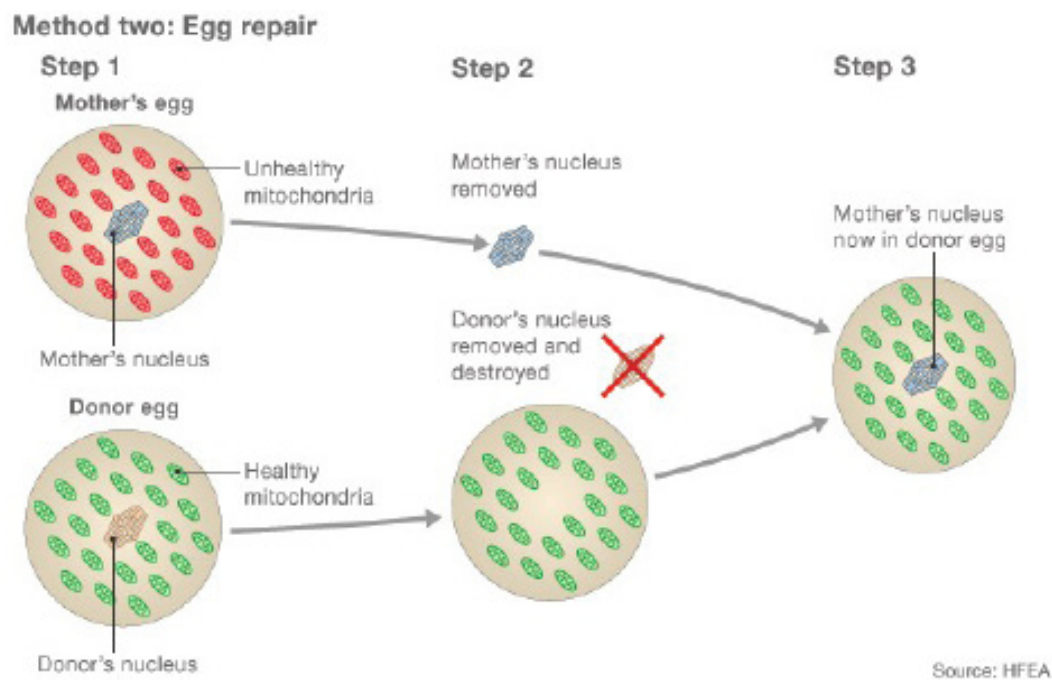

Figure 2. Step 1: Eggs from a mother with damaged mitochondria and a donor with healthy mitochondria are collected. Step 2: The majority of the genetic material is removed from both eggs. Step 3: The mother's genetic material is inserted into the donor egg, which can be fertilised by sperm ${ }^{3}$.

exist surrounding the potential for the

technology to be used to enhance and create babies with desirable traits. A review by the London-based Nuffield Council on Bioethics asserts that MRT is ethical ${ }^{7}$ and clear guidelines and regulations have been drafted to calm "designer baby" concerns, explicitly stating that mtDNA disease is the only indication for oocyte modification ${ }^{8}$. The potential for MRT is huge and ideas are circulating on how the technique may be useful in other treatments, such as age-related infertility. What about heritable diseases affecting the nuclear genome? Current draft regulations do not consider these possibilities. The need for ethical debate concerning the bounds and regulation of MRT must continue.

\section{Social concerns}

The reference to MRT in the media as three-person babies or three-parent babies does not accurately reflect the resulting offspring's genes and stimulates legal fears over parenting. A more accurate description would be 2.001-person IVF since the DNA from the donor egg amounts to less than one-tenth of one percent of the resulting embryo's genes ${ }^{5}$. Draft regulations in the UK recommend considering the mitochondrial donor akin to an organ donor and not legally a parent ${ }^{8}$. Just like sperm and egg regulations, the parents are the people raising the child and the donor woman would remain anonymous.

\section{MRT in Canada}

In Canada human trials of MRT are illegal and there is little, if any, discussion on the matter. Developed to discourage misuse of reproductive technology, the Assisted Human Reproduction Act of 2004 prohibits any gene altercations in a cell or embryo that may be transmitted to descendants ${ }^{9}$. How this legislation has influenced the lack of debate is unclear but Canada will likely be forced into the discussion once data returns on the safety and efficacy of the UK trials.

\section{Conclusion}

Genetic intervention studies will soon be a reality in the UK. The vertical transmission of donor mtDNA has sparked heated debate concerning heritable genetic modification and requires close monitoring of human trials. Canada appears to be waiting on the results of these trials before initiating any ethical or regulatory discussion, an approach that may hinder rapid access to modern advances that may prevent progressive and often brutal inherited mtDNA disease in Canadian children.

\section{References}

1. Mattman A, Sirrs S, Mezei MM, Salvarinova-Zivkovic R, Alfadhel M, Lillquist Y. Mitochondrial disease clinical manifestations: an overview. BCMJ. 2011 May; 53(4): 183-187.

2. MitoCanada. Annual report 2012: a TransCanada journey [Internet]. Brantford, Ontario: MitoCanada Foundation; June 2012 [cited 2015 March 27]. Available from: http://www.mitocanada.org/wp-content/ uploads/2012/08/Annual-Report-2012-for-MITO-June-9th-FINAL.pdf

3. Craven L, Tuppen HA, Greggains GD, Harbottle S, Murphy JL, Cree LM, Murdoch AP, Chinnery PF, Taylor RW, Lightowlers RN, Herbert M, Turnbull DM. Pronuclear transfer in human embryos to prevent transmission of mitochondrial DNA disease. Nature. 2010 May; 465(7294): 82-85. 
4. Tachibaba M, Sparman M, Sritanaudomchai H, Ma H, Clepper L, Woodward J, Li Y, Ramsey C, Kolotushkina O, Shoukhrat M. Mitochondrial gene replacement in primate offspring and embryonic stem cells. Nature. 2009 Sept; 461(7262): 367-372.

5. Gallagher J. MPs say yes to three-person babies. BBC News [Internet]. 2015 February 3 [cited 2015 Feb 7]. Available from: http://www.bbc.com/news/ health-31069173

6. Human Fertilisation and Embryology Authority (HFEA). Third scientific review of the safety and efficacy of methods to avoid mitochondrial disease through assisted conception: 2014 update [Internet]. 2014 June 2 [cited 2015 Feb 7]. Available from: http://www.hfea.gov.uk/docs/Third_ Mitochondrial_replacement_scientific_review.pdf

7. Nuffield Council on Bioethics. Novel techniques for the prevention of mitochondrial DNA disorders: an ethical review [Internet]. 2012 June [cited 2015 Feb 7]. Available from: http://nuffieldbioethics.org/project/ mitochondrial-dna-disorders/

8. Department of Health, UK. Mitochondrial donation: a consultation on draft regulations to permit the use of new treatment techniques to prevent the transmission of a serious mitochondrial disease from mother to child [Internet]. 2014 February [cited 2015 March 27]. Available from: https:// www.gov.uk/government/uploads/system/uploads/attachment_data/ file/285251/mitochondrial_donation_consultation_document_24_02_14_ Accessible_V0.4.pdf.

9. Canada, Department of Justice Canada. Assisted Human Reproduction Act, S.C. 2004, c2 [Internet]. 2004 [updated 2015 March 24; cited 2015 March 27]. Available from: http://laws-lois.justice.gc.ca/PDF/A-13.4.pdf

10. Bredenoord A, Braude P. Ethics of mitochondrial gene replacement: from bench to bedside. BMJ. 2010 Nov; 341:c6021.

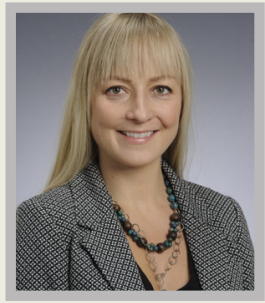

\section{Jennifer Kramer}

Jennifer Kramer is currently pursing a PhD (Nursing) at the University of Saskatchewan, the institution where she also obtained her BSN and MN degrees. Her research examines the relation between the severity of nausea and vomiting in pregnancy and maternal mental health, as well as the effects of these experiences on the mother and child postpartum at one, three, and five-year intervals. This research stems from her experience as a registered nurse (RN) in the areas of labour and birth and adult psychiatry. 